\title{
Increased expression of ACTH (MC2R) and androgen $(A R)$ receptors in giant bilateral myelolipomas from patients with congenital adrenal hyperplasia
}

\author{
Madson Q Almeida ${ }^{1,2}$, Laura C Kaupert ${ }^{1}$, Luciana P Brito ${ }^{1}$, Antonio M Lerario ${ }^{1}$, Beatriz M P Mariani ${ }^{1}$, Marta Ribeiro ${ }^{3}$,
} Osmar Monte ${ }^{3}$, Francisco T Denes ${ }^{4}$, Berenice B Mendonca ${ }^{1}$ and Tânia ASS Bachega ${ }^{1 *}$

\begin{abstract}
Background: Although chronic adrenocorticotropic hormone (ACTH) and androgen hyperstimulation are assumed to be involved in the pathogenesis of adrenal myelolipomas associated with poor-compliance patients with congenital adrenal hyperplasia (CAH), the expression of their receptors has not yet been demonstrated in these tumors so far.

Methods: We analyzed Melanocortin 2 receptor (MC2R), Androgen Receptor (AR), Leptin (LEP), and Steroidogenic factor 1 (SF1) expression using real-time qRT-PCR in two giant bilateral adrenal myelolipomas from two untreated simple virilizing $\mathrm{CAH}$ cases and in two sporadic adrenal myelolipomas. In addition, the X-chromosome inactivation pattern and CAG repeat numbers in AR exon 1 gene were evaluated in the 4 cases.

Results: The MC2R gene was overexpressed in myelolipomas from 3 out of 4 patients. AR overexpression was detected in 2 tumors: a giant bilateral myelolipoma in a CAH patient and a sporadic case. Simultaneous overexpression of $A R$ and MC2R genes was found in two of the cases. Interestingly, the bilateral giant myelolipoma associated with CAH that had high androgen and ACTH levels but lacked $M C 2 R$ and $A R$ overexpression presented a significantly shorter $A R$ allele compared with other tumors. In addition, X-chromosome inactivation pattern analysis showed a polyclonal origin in all tumors, suggesting a stimulatory effect as the trigger for tumor development.
\end{abstract}

Conclusion: These findings are the first evidence for $M C 2 R$ or $A R$ overexpression in giant bilateral myelolipomas from poor-compliance CAH patients.

Keywords: Adrenal myelolipoma, Congenital adrenal hyperplasia, ACTH, MC2R, Androgen receptor, Clonality analysis

\section{Background}

Adrenal myelolipomas are benign non-functioning tumors composed of adipose tissue and hematopoietic elements resembling bone marrow [1]. These tumors account for up to $8 \%$ of adrenal incidentalomas [2]. Adrenal myelolipomas are usually asymptomatic but can cause compressive symptoms. Typically, they have a fat signal intensity on $\mathrm{T}_{1}$-weighted magnetic resonance (RM) [2]. Interestingly, myelolipomas have been described in the setting of

\footnotetext{
* Correspondence: tbachega@usp.br

'Divisão de Endocrinologia e Metabologia, Laboratório de Hormônios e Genética Molecular/LIM42, Hospital das Clínicas da Faculdade de Medicina da Universidade de São Paulo, Av. Dr. Enéas de Carvalho Aguiar, 155, 2 andar, Bloco 6, São Paulo, SP 05403-900, Brasil

Full list of author information is available at the end of the article
}

adrenocorticotropic hormone (ACTH) excess, such as classical congenital adrenal hyperplasia $(\mathrm{CAH})$ [1], Cushing disease [3] and Nelson syndrome [4]. Recently, Nermoen et al. [5] reported a $4 \%$ frequency of adrenal myelolipomas (4 out of 101; 3 of them with bilateral myelolipomas) in a large group of unselected patients with 21-hydroxylase deficiency $(21 \mathrm{OH})$. Adrenal myelolipomas can rarely present as giant bilateral masses, but approximately 14 cases of giant bilateral myelolipomas have been described in association with $\mathrm{CAH}$ [1,5-9].

Several mechanisms have been proposed to explain the pathogenesis of adrenal myelolipomas, such as embryonic bone marrow rests in adrenal tissue, adrenal embolization of bone marrow cells and metaplasia of 
adrenocortical cells [10,11]. Although chronic ACTH hyperstimulation is thought to be involved in the pathogenesis of adrenal myelolipomas based primarily on the finding of bilateral tumors in poor-compliance $\mathrm{CAH}$ patients, this hypothesis remains to be confirmed. Melanocortin 2 receptor $(M C 2 R)$ is selectively activated by ACTH and encodes a G-protein coupled receptor. Indeed, $M C 2 R$ and androgen receptor $(A R)$ expression was previously evaluated in a single case of giant bilateral myelolipoma in a $\mathrm{CAH}$ patient and was negative using a semiquantitative approach [1]. However, considering the high frequency of association between giant bilateral myelolipomas and $C A H$, we hypothesized that $A C T H$ and $A R$ might have a role in the pathogenesis of myelolipomas.

In this study, we analyzed $M C 2 R$ and $A R$ expression as well as nCAG $A R$ repeat numbers in two bilateral giant myelolipomas from $\mathrm{CAH}$ patients and two unilateral sporadic myelolipomas. Additionally, clonality was evaluated through $\mathrm{X}$-chromosome inactivation analysis. Our data indicated that $M C 2 R$ and/or $A R$ were involved in the pathogenesis of myelolipomas associated with $\mathrm{CAH}$, suggesting a stimulatory hormonal effect as a trigger for tumor growth. These findings are the first evidence for $\mathrm{ACTH}$ and androgen roles in giant bilateral myelolipomas in $\mathrm{CAH}$ patients and sporadic cases.

\section{Methods}

The study was approved by the Ethics Committee of Hospital das Clínicas, São Paulo University and from Santa Casa de Misericordia Hospital, and informed written consent was obtained from all patients for participate in the study and for the publication of data and/or images. Blood and tissue samples were collected from the patients after informed consent was obtained. Four patients with myelolipomas were evaluated in this study: two giant bilateral adrenal myelolipomas from two untreated simple virilizing $\mathrm{CAH}$ cases and two sporadic adrenal myelolipomas. Abdominal masses were identified with computed tomography $(\mathrm{CT})$ or magnetic resonance imaging (MRI), and pathology confirmed myelolipoma after bilateral or unilateral adrenalectomy.

\section{Quantitative real-time PCR}

After surgical resection, tumor fragments were immediately frozen in liquid nitrogen and stored at $-80^{\circ} \mathrm{C}$ until total RNA extraction using Trizol reagent (Invitrogen, Carlsbad, CA). cDNA was generated using a High Capacity kit (Applied Biosystems, Foster City, CA, USA). Quantitative real-time PCR (qRT-PCR) was performed with an ABI Prism 7700 sequence detector using TaqMan gene expression assays (Applied Biosystems, Foster City, CA). The assay identifications were the following: MC2R (Hs00265039_s1), AR (Hs00907244_m1), SF1 (Hs00610436_m1) and LEP (Hs01084494_m1). Beta- actin (ACTB) and Glyceraldehyde-3-phosphate dehydrogenase (GAPDH) genes were used as endogenous genes. A commercial pool of adipose tissue and adrenal tissue was used for comparisons (CLONTECH, BioChain, and Ambion). Relative quantification was performed using the $2^{-\Delta \Delta C T}$ method [12]. Overexpression was defined as a two-fold change in comparison to normal adipose tissue.

\section{X-Chromosome inactivation and CAG repeat numbers of the $A R$ gene}

Genomic DNA was obtained from tumors using standard procedures. The X-chromosome inactivation pattern and CAG repeat numbers were determined as previously described [13]. Briefly, PCR amplification of the CAG repeat region of HpaII-digested and undigested samples was carried out using primers flanking the region of interest: 5'-GCTGTGAAGGTTGCTGTTCCTC-3' and 5'-HEX-GTGCGCGAAGTGATCCAGAA-3'. All samples were separately amplified in $50 \mu \mathrm{L}$ reactions containing $1 \mathrm{x}$ PCR reaction buffer with $1.5 \mathrm{mM}$ of $\mathrm{MgCl}_{2}$, $200 \mu \mathrm{M}$ of deoxynucleotides, $15 \mathrm{pmol}$ of each primer and $1 \mathrm{U}$ of Taq DNA Polymerase (Amersham-Pharmacia, Uppsala, Sweden). Amplifications were performed under the following conditions: initial denaturation at $97^{\circ} \mathrm{C}$ for $5 \mathrm{~min}$; amplification for 35 cycles with denaturation at $97^{\circ} \mathrm{C}$ for $1 \mathrm{~min}$, annealing at $54^{\circ} \mathrm{C}$ for $45 \mathrm{~s}$ and extension at $72^{\circ} \mathrm{C}$ for $45 \mathrm{~s}$; and one final extension at $72^{\circ} \mathrm{C}$ for $30 \mathrm{~min}$. Two and $4 \mu \mathrm{L}$ of PCR products from undigested and digested samples, respectively, were submitted to capillary electrophoresis on ABI PRISM 310 Genetic Analyzer (Applied Biosystems, Foster City, CA, USA) and analyzed by GeneScan software to determine the sizes of the amplified fragments, which were established through comparisons with a size marker and a sample with a known CAG repeat number in the same run. These sizes were correlated with CAG repeat numbers, as previously shown in our lab [14]. Digested and undigested samples were also assayed in the same run, and the peak height of each allele was used to determine the X-chromosome inactivation pattern.

\section{Results}

\section{Clinical data}

Patient 1 was a 35-yr-old woman who presented with the simple virilizing form of CAH [p.E351V and exon 6 cluster (p.I236N, p.V237E, and p.M239K) mutations in a compound heterozygote state in the CYP21A2 gene]. CT scan revealed giant bilateral adrenal myelolipomas (left, $14 \times 14 \times 10 \mathrm{~cm}$; right $8.9 \times 8.3 \times 8.0 \mathrm{~cm}$ ) with fat component density. She did not present to clinical follow-up and had not received any medications in the last $15 \mathrm{yr}$. Hormonal evaluation revealed extremely increased levels: basal 17OH-progesterone (17-OHP) $192 \mathrm{ng} / \mathrm{mL}$, ACTH 

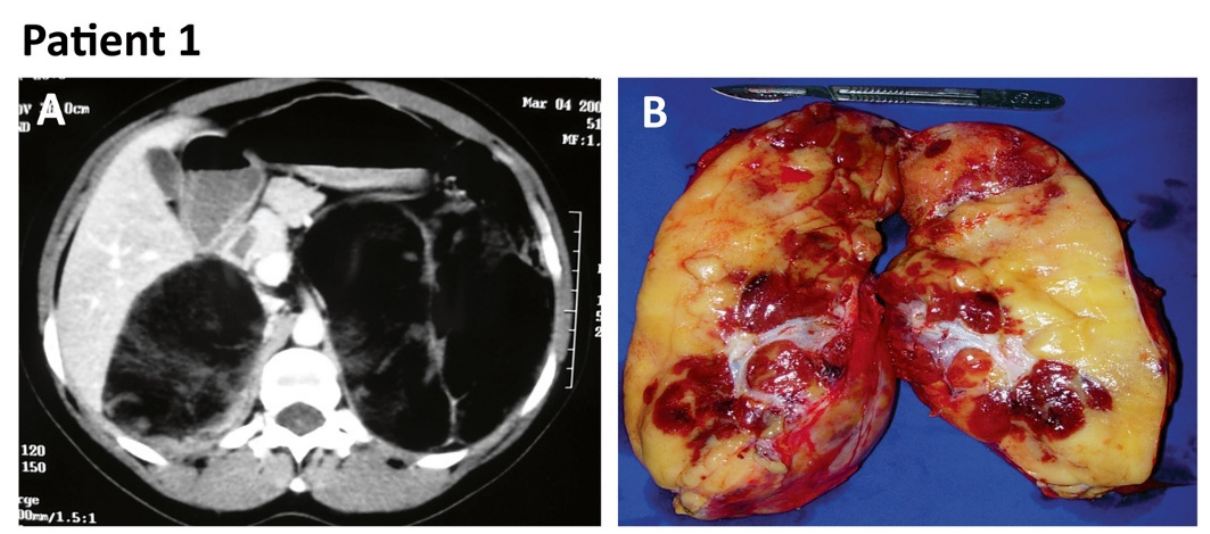

\section{Patient 2}
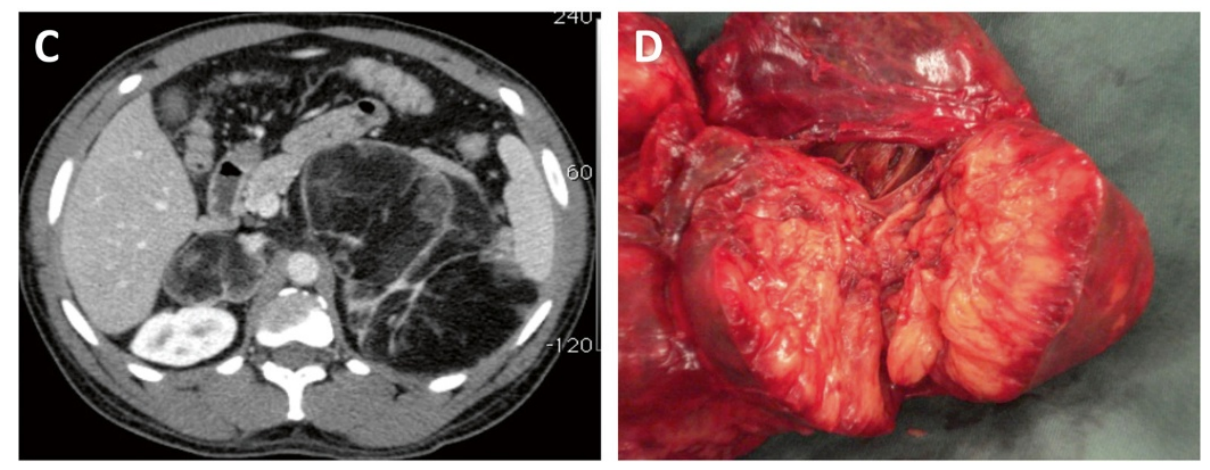

Figure 1 Imaging and histopathology of giant bilateral myelolipomas in patients with congenital adrenal hyperplasia. Patient 1: A, CT scan showing heterogeneous bilateral myelolipomas (left, $14 \times 14 \times 10 \mathrm{~cm}$; right $8.9 \times 8.3 \times 8.0 \mathrm{~cm}$ ). B, Macroscopic aspect of left adrenal myelolipomas. Patient 2: C, CT scan revealing large bilateral myelolipomas (left, $16 \times 13 \times 9.0 \mathrm{~cm}$; right, 5.3x $4.3 \times 6.9 \mathrm{~cm}$ ). D, Macroscopic appearance of left adrenal myelolipomas.

$1,172 \mathrm{pg} / \mathrm{mL}$, total testosterone $949 \mathrm{ng} / \mathrm{dL}$ and androstenedione $17 \mathrm{ng} / \mathrm{mL}$ (Figures $1 \mathrm{~A}$ and $1 \mathrm{~B}$ ).

Patient 2 was a 52-yr-old woman who presented with the simple virilizing form of CAH (IVS2-13A/C > G/ p.I172N). CT scan revealed giant bilateral adrenal myelolipoma (left, $16 \times 13 \times 9.0 \mathrm{~cm}$; right, $5.3 \times 4.3 \times 6.9 \mathrm{~cm}$ ) with fat component density (Figures 1C and 1D). This patient had never been previously treated, and hormonal evaluation also revealed increased serum levels: $17-\mathrm{OHP} 120 \mathrm{ng} / \mathrm{mL}$, total testosterone $720 \mathrm{ng} / \mathrm{dL}$ and androstenedione $39 \mathrm{ng} / \mathrm{mL}$. $\mathrm{ACTH}$ measurement was not available. Both $\mathrm{CAH}$ patients were severely virilized during adolescence and changed to male social sex. They sought medical assistance due to abdominal pain.

Patient 3 (a 48-yr-old female) and patient 4 (a 40-yrold female) presented with incidental findings of sporadic unilateral adrenal myelolipoma ranging from 8 to $10 \mathrm{~cm}$ in the major diameter. MRI demonstrated fat tissue signal in both masses. The patients did not present any clinical presentation of hyperandrogenism and non-classical $\mathrm{CAH}$ was rule-out by clinical evaluation.

Briefly, the histopathological analysis of all tumors showed lobes of mature adipose tissue mixed with abundant hematopoietic tissue consisting of all three hematopoietic elements with mature and precursor cells. There were islets of cells from the zones of the adrenal cortex in the periphery of tumors as well as between hematopoietic and lipoid cells.

\section{Expression study}

The $M C 2 R$ gene was overexpressed in the myelolipomas of 3 out of 4 patients (Table 1). MC2R expression was correlated with SF1 mRNA levels in the same tumors. Only the myelolipoma diagnosed in patient 1 did not

Table 1 nCAG repeat numbers and $A R, M C 2 R, L E P$ and SF1 gene expression in myelolipomas

\begin{tabular}{lccccc}
\hline Patients & nCAG & $\boldsymbol{A R}^{*}$ & $\boldsymbol{M C 2}^{*}$ & LEP* & SF $^{*}$ \\
\hline 1 & $15 / 21$ & 0.1 & 0.6 & 0.2 & 1.0 \\
2 & $20 / 23$ & 8.6 & 853 & 2.1 & 365 \\
3 & $24 / 25$ & 0.1 & 99 & 0.04 & 6.3 \\
4 & $22 / 30$ & 5.0 & 3214 & 6.1 & 259 \\
Adrenal pool & & 0.03 & 481 & 0 & 2462 \\
\hline
\end{tabular}

${ }^{*}$ An adipose tissue pool was used as the reference sample in the expression analysis. 
show $M C 2 R$ overexpression. As expected, $M C 2 R$ mRNA levels were higher in the adrenal pool.

The $A R$ gene was overexpressed in myelolipomas from patients 2 and 4. Low $A R$ expression levels were found in the other cases (patients 1 and 3). $A R$ expression was correlated with $L E P$ expression in all tumors.

\section{Clonality and nCAG repeat number analysis}

$\mathrm{X}$-chromosome inactivation pattern analysis revealed a polyclonal origin in all tumors. In addition, all tumors were informative, and nCAG repeat numbers varied from 20 to 30 , except in the tumor from patient 1 , which had a short allele (15 repeats) (Table 1$)$.

\section{Discussion}

The pathogenesis of adrenal myelolipomas is unclear, but several mechanisms have been proposed to underlie the etiology. One of the hypothesis is that hematopoietic and fat elements could derive from common progenitor cells secondary to stimulatory factors [15]. In this study, we demonstrated that the $M C 2 R$ gene was overexpressed in 3 out of 4 myelolipomas. Among these 3 cases, 1 giant bilateral myelolipoma was associated with $\mathrm{CAH}$, and two patients presented sporadic myelolipomas. Chronic ACTH hyperstimulation has been proposed as the main hypothesis to explain the higher frequency of giant and bilateral myelolipomas in poor-compliance CAH patients, but it has never been previously demonstrated. Lack of $M C 2 R$ gene expression was demonstrated in a giant adrenal myelolipoma associated with $\mathrm{CAH}$ employing a semi-quantitative approach to analyze mRNA expression [1]. Therefore, to our knowledge, our finding is the first evidence of $M C 2 R$ overexpression in myelolipomas. $M C 2 R$ overexpression was found in all but one case. Despite of chronic ACTH hyperstimulation, myelolipoma from patient 1 did not present $M C 2 R$ overexpression.

Androgen receptors have also been implicated in the pathogenesis of myelolipomas associated with poorly controlled $\mathrm{CAH}$ patients [1]. In the current study, $A R$ overexpression was detected in 2 tumors: a giant bilateral myelolipoma in a CAH patient and a sporadic case. $A R$ expression was previously assessed in a single case of bilateral myelolipoma associated with $\mathrm{CAH}$ using a semi-quantitative technique, but the results were negative [1]. Here, we employed a more sensitive approach to study $A R$ and $M C 2 R$ expression. The overexpression of $A R$ and $M C 2 R$ genes was concomitantly found in two of the cases.

It has been postulated that androgens, through their interaction with androgen receptors, may play an important role in the development of specific tumors, such as ovarian and prostate cancer [16,17]. Exon 1 of the $A R$ gene contains highly polymorphic trinucleotide repeats, and the length of the $\mathrm{nCAG}$ repeat segment is inversely correlated with the transactivation function of the $A R$ gene [18]. Interestingly, the case of bilateral giant myelolipoma associated with $C A H$ that lacked $M C 2 R$ and $A R$ overexpression had a shorter $A R$ allele compared with the other tumors, suggesting that this $A R$ genotype in the context of very high androgen levels may play a causative role in the development of myelolipomas. The stimulatory effect of $M C 2 R$ and $A R$ overexpression or increased $A R$ transactivation activity in the development of adrenal myelolipomas could be reinforced by the finding of a polyclonal origin in all tumors described here.

\section{Conclusion}

In conclusion, we first demonstrated here $M C 2 R$ or $A R$ overexpression in giant bilateral myelolipomas from poorcompliance $\mathrm{CAH}$ patients. Therefore, we can speculate that chronic $\mathrm{ACTH}$ and androgen stimulation may play a causative role in myelolipomas of poorly controlled CAH patients. In addition, X-chromosome inactivation pattern analysis revealed a polyclonal origin in all tumors, suggesting a stimulatory effect as a trigger for tumor development.

\section{Abbreviations}

$\mathrm{CAH}$ : Congenital adrenal hyperplasia; ACTH: Adrenocorticotropic hormone; MC2R: Melanocortin 2 receptor; SF1: Steroidogenic factor 1; LEP: Leptin; AR: Androgen Receptor; ACTB: Beta-actin; GAPDH: Glyceraldehyde-3phosphate dehydrogenase.

\section{Competing interest}

The authors declared that they have no competing interest.

\section{Author contribution}

MQA: data analysis, interpretation, drafting the manuscript. LCK: data acquisition, data analysis. LPB: data acquisition, data analysis, statistical analysis. AML: data acquisition, statistical analysis. BMP. Mariani: data acquisition, data analysis. MR: data acquisition, critical revision. OM: data acquisition, critical revision. FTD: performed the laparoscopic procedure of patients included in this study. BBM: critical revision, supervision. TASSB: conception and design, drafting the manuscript, critical revision, supervision. All authors read and approved the final manuscript.

\section{Acknowledgments}

We thank Dr. Sandra M. Villares for providing the mRNA pool of adipose tissue used in this study.

\section{Author details}

'Divisão de Endocrinologia e Metabologia, Laboratório de Hormônios e Genética Molecular/LIM42, Hospital das Clínicas da Faculdade de Medicina da Universidade de São Paulo, Av. Dr. Enéas de Carvalho Aguiar, 155, 2 andar, Bloco 6, São Paulo, SP 05403-900, Brasil. ${ }^{2}$ Instituto do Câncer do Estado de São Paulo (ICESP), Faculdade de Medicina da Universidade de São Paulo, São Paulo, Brasil. ${ }^{3}$ Unidade de Endocrinologia e Metabologia, Departamento de Clínica Médica, Faculdade de Ciências Médicas da Santa Casa de Misericórdia de São Paulo, São Paulo, Brasil. ${ }^{4}$ Serviço de Urologia, Hospital das Clínicas, Faculdade de Medicina da Universidade de São Paulo, São Paulo, Brasil.

Received: 28 January 2014 Accepted: 8 May 2014 Published: 12 May 2014

\section{References}

1. Hagiwara H, Usui T, Kimura T, Tagami T, Naruse M, Minamiguchi S, Kato T, Okuno H, Shimatsu A: Lack of ACTH and androgen receptor expression in a giant adrenal myelolipoma associated with 21-hydroxylase deficiency. Endocr Pathol 2008, 19(2):122-127. 
2. Mansmann G, Lau J, Balk E, Rothberg M, Miyachi Y, Bornstein SR: The clinically inapparent adrenal mass: update in diagnosis and management. Endocr Rev 2004, 25(2):309-340

3. Hisamatsu H, Sakai H, Tsuda S, Shigematsu K, Kanetake H: Combined adrenal adenoma and myelolipoma in a patient with Cushing's syndrome: case report and review of the literature. Int J Urol 2004, 11(6):416-418.

4. Maschler I, Rosenmann E, Ehrenfeld EN: Ectopic functioning adrenocortico-myelolipoma in longstanding Nelson's syndrome. Clin Endocrinol (Oxf) 1979, 10(5):493-497.

5. Nermoen I, Rorvik J, Holmedal SH, Hykkerud DL, Fougner KJ, Svartberg J, Husebye ES, Lovas K: High frequency of adrenal myelolipomas and testicular adrenal rest tumours in adult Norwegian patients with classical congenital adrenal hyperplasia because of 21-hydroxylase deficiency. Clin Endocrinol (Oxf) 2011, 75(6):753-759.

6. German-Mena E, Zibari GB, Levine SN: Adrenal myelolipomas in patients with congenital adrenal hyperplasia: review of the literature and a case report. Endocr Pract 2011, 17(3):441-447.

7. Ioannidis O, Papaemmanouil S, Chatzopoulos S, Paraskevas G, Konstantara A, Kotronis A, Kakoutis E, Makrantonakis A: Giant bilateral symptomatic adrenal myelolipomas associated with congenital adrenal hyperplasia. Pathol Oncol Res 2011, 17(3):775-778.

8. McGeoch SC, Olson S, Krukowski ZH, Bevan JS: Giant bilateral myelolipomas in a man with congenital adrenal hyperplasia. J Clin Endocrinol Metab 2012, 97(2):343-344.

9. Mermejo LM, Elias Junior J, Saggioro FP, Tucci Junior S, Castro M, Moreira AC, Elias PC: Giant adrenal myelolipoma associated with 21-hydroxylase deficiency: unusual association mimicking an androgen-secreting adrenocortical carcinoma. Ara Bras Endocrinol Metabol 2010, 54(4):419-424.

10. Plaut A: Myelolipoma in the adrenal cortex; myeloadipose structures. Am J Pathol 1958, 34(3):487-515.

11. Dean G: Myelolipoma of the adrenal gland. Scott Med J 1971, 16(12):513-518.

12. Livak KJ, Schmittgen TD: Analysis of relative gene expression data using real-time quantitative PCR and the 2(-Delta Delta C(T)) Method. Methods 2001, 25(4):402-408.

13. Kaupert LC, Billerbeck AE, Brito VN, Mendonca BB, Bachega TA: Could the leukocyte $\mathrm{x}$ chromosome inactivation pattern be extrapolated to hair bulbs? Horm Res Paediatr 2010, 73(4):238-243.

14. Rocha RO, Billerbeck AE, Pinto EM, Melo KF, Lin CJ, Longui CA, Mendonca $B B$, Bachega TA: The degree of external genitalia virilization in girls with 21-hydroxylase deficiency appears to be influenced by the CAG repeats in the androgen receptor gene. Clin Endocrinol (Oxf) 2008, 68(2):226-232.

15. Selye $\mathrm{H}$, Stone $\mathrm{H}$ : Hormonally induced transformation of adrenal into myeloid tissue. Am J Pathol 1950, 26(2):211-233.

16. Kim SC, Ju W, Mahavni V, Geisler JP, Buller RE: CAG repeat length in exon 1 of the androgen receptor gene is related to age of diagnosis but not germ line BRCA1 mutation status in ovarian cancer. Int I Gynecol Cancer 2006, 16(Suppl 1):190-194.

17. Gururajan M, Posadas EM, Chung LW: Future perspectives of prostate cancer therapy. Transl Androl Urol 2012, 1(1):19-32.

18. Wu MH, Chou YC, Yu CP, Yang T, You SL, Chen CJ, Sun CA: Androgen receptor gene CAG repeats, estrogen exposure status, and breast cancer susceptibility. Eur J Cancer Prev 2008, 17(4):317-322.

\section{doi:10.1186/1472-6823-14-42}

Cite this article as: Almeida et al.: Increased expression of ACTH (MC2R) and androgen $(A R)$ receptors in giant bilateral myelolipomas from patients with congenital adrenal hyperplasia. BMC Endocrine Disorders 2014 14:42

\section{Submit your next manuscript to BioMed Central and take full advantage of:}

- Convenient online submission

- Thorough peer review

- No space constraints or color figure charges

- Immediate publication on acceptance

- Inclusion in PubMed, CAS, Scopus and Google Scholar

- Research which is freely available for redistribution 